\title{
Electronic fit notes: sickness certification in the new decade
}

Although estimates of the costs of sickness absence to the UK economy vary, as do the methods used to quantify these figures, ${ }^{1,2}$ it is clear that these costs exceed the total NHS budget. Annual costs of sickness absence and worklessness associated with ill health are estimated to exceed $£ 100$ billion per year. ${ }^{2}$ The costs to UK business of mental ill health alone are estimated at £26 billion each year. ${ }^{3}$ Despite these huge costs, this remains an under-researched area, ${ }^{4}$ and most of the research that has been done has been conducted in Scandinavia where the welfare and certification systems differ significantly from those in the UK and elsewhere. ${ }^{5}$

There are clear links between deprivation and worklessness and ill health. About $7 \%$ of the workforce are in receipt of long-term illness-related benefit. An alarmingly low proportion of them ever return to paid employment, locking themselves and their dependents into long-term deprivation and social exclusion, ${ }^{2}$ particularly in areas of low employment with up to a tenfold variation between UK regions. ${ }^{6}$ The arguments for enhanced family income for those on longterm sickness benefits are less robust since the welfare reforms and minimum wage have been introduced since 1997 . Furthermore, recent modifications to disability legislation require employers to make reasonable workplace adjustments that can facilitate access to paid work for disabled adults and also accommodate the consequences of illness within the workplace.

However, critics of the government's aim to reverse the drift towards increasing proportions of the workforce on long-term sickness welfare benefits, suggest that many of those targeted as potentially fit to return to the workforce are those least likely to be offered work, particularly in times of recession, and represent hidden unemployment. ${ }^{6}$

While the Department for Work and Pensions (DWP) can track trends in long- term sickness and the associated certification, less is known about the causes and progress of sickness absence of less than 6 months. Research using duplicate sicknotes and employer surveys suggests that mild to moderate mental health illness represents the largest diagnostic group in the UK, above musculoskeletal problems, which still predominate in Scandinavia. Research suggests that in addition to the cause of illness, increasing age, being male, and deprivation also increase the risk of sustained absence..$^{2,7}$

\section{BENEFITS OF WORK}

There is a growing clinical consensus that good work is good for health and that avoiding sickness absence or encouraging an early return to work, including phased returns in terms of times and work modifications, enhances recovery, both physical and psychological. ${ }^{2}$ This links to the shift away from sickness certification focused on absence, to the concept of certification targeted at return to work or modified work during a period of ill health: the 'fit note'. The fit note is to be introduced on 6 April 2010, in paper form initially, although it is intended to introduce the electronic format later this year. This month's Journal includes a report of the recent DWP-funded electronic fit note pilot. ${ }^{8}$ There have been intermittent flurries of news about this significant change in the procedures and principals for certifying fitness for work since they were first proposed in Dame Carol Black's report. ${ }^{2}$

\section{LIMITATIONS OF THE CURRENT SYSTEM}

In the UK those who feel unable to work through ill health self-certify for up to 1 week, but require a certificate from their GP recommending further sickness absence or giving a recommended return to work date (if this is within 2 weeks). Thus, the bulk of certification work focuses on absence rather than judgements of function, prognosis, and rehabilitation. Only a minority of GPs have training or experience in occupational health, but many large employers have access to this service, and small and medium employers (including general practices concerned about their own staff) can now access occupational health advice via the recently introduced DWPfunded helpline (Health for Work Adviceline).

There is evidence from qualitative research and small surveys that GPs vary in their attitudes and approach towards this certification role,,$^{9,10}$ and in the extent to which they distinguish between those in employment or seeking employment. They may use 'codes' that they hope officials will recognise when they are unsure of the need for absence. These may be on other forms as claimants pass to longer-term absence and include adding 'genuine' contrasting with 'the patient reports', omitting details, or leaving sections of the forms blank. ${ }^{11}$ However GPs have been providing evidence to employers about fitness for work for over 150 years, ${ }^{11}$ so it is likely that an expectation that they will continue to undertake this role will persist into the foreseeable future.

\section{THE FIT NOTE}

Sallis et al's pilot ${ }^{8}$ compares the fit note with the current sickness certification system and suggests that GPs were able to complete fit notes and make decisions within the new framework, with significantly higher proportions being considered fit for some work rather than not at all, suggesting that this option is relevant and a key development beyond the all-or-none traditional choice. The GP's role remains limited within the new system. The fit note does not require GPs to make detailed functional assessments; that is for the employer to do once the 'may be fit for work' recommendation is made. The employer must consider adjustments, but if they cannot be made 
then the patient cannot be required to work as long as they remain certified as not completely fit to return. Thus, the GP is expected to assess the potential impact of illness on function and negotiate with the patient how this may have an impact on their work ability, and advise the employer accordingly.

While GPs may predictably perhaps complain that they do not have the appropriate training or skills to formally assess work ability in patients with ill health (that is the role of occupational health specialists), we can hardly claim as a profession that we lack communication skills, the facilities for comprehensive record-keeping, or facilities to ensure a reasonable degree of continuity of care. GPs traditionally pride themselves on the strengths of the GP system to facilitate strong therapeutic relationships and, thus, to negotiate health interventions. Recent research into sickness absence consultations provides evidence that GPs are skilled at negotiating sickness certificate consultations as well (R Byng and $\mathrm{P}$ Hodgson, personal communication, 2009). There are some resources available to support our decision-making. The Royal Colleges provide guidance on the length of sickness absence likely to be needed for a range of conditions that are included on the DWP desktop guide for GPs. ${ }^{12}$ The DWP also has guides for both GPs and employers on the fit note on its website. $^{13}$

The introduction of the fit note signifies the practical impact of the cultural shift in attitudes to work and welfare in the 21st century. GPs will differ in their opinions about the expectation that more adults of working age should be enabled to work, and that GPs are being asked to assist employees and employers to manage sickness in the workplace more actively to reduce sickness absence. We are being required to change our approach and practice in a relative absence of robust evidence to guide us, and to think in relatively unfamiliar ways. However, GPs certainly have the core communication, clinical, and negotiating skills that equip them to manage this modified role, and perhaps it will ultimately make such conversations about fitness for work a more active component of care, and less of a source of tension and concern. Sallis et al's article suggests that this optimistic view is warranted, but as always, further research, and time, will tell.

\section{Mark B Gabbay,}

Professor of General Practice, Head of Division of Primary Care, University of Liverpool, Liverpool.

\section{Provenance}

Commissioned; not peer reviewed.

\section{REFERENCES}

1. Woolf S, Martindale A-M, Stanistreet D, et al. DWP project on the feasibility of SSP data collection. (Research report 427) London: Department for Work and Pensions, 2007.

2. Black C. Working for a healthier tomorrow. London: TSO, 2008

3. Sainsbury Centre for Mental Health. Mental health at work: developing the business case. (Policy Paper 8). London: Sainsbury Centre for Mental Health, 2007.

4. National Institute for Health and Clinical Excellence. Managing long-term sickness absence and incapacity for work. Public Health Guidance 19. London: NICE 2009.

5. Swedish Council on Technology Assessment in Health

Care. Sickness absence: causes, consequences, and physicians' sickness certification practice. A systematic literature review by the Swedish Council on Technology Assessment in Health Care (SBU). Scand J Public Health Suppl 2004; 63: 3-263.

6. Fothergill S, Wilson I. A million off incapacity benefit: how achievable is Labour's target? Cambridge J Econ 2007; 31: 1007-1023.

7. Shiels C, Gabbay MB. Patient, clinician and general practice factors in long-term certified sickness. Scand J Pub Health 2007; 35(3): 250-256.

8. Sallis A, Birkin R, Munir F. Working towards a 'fit note': an experimental vignette survey of GPs. $\mathrm{Br} \mathrm{J} \mathrm{Gen}$ Pract 2010; 60: 245-250.

9. Hiscock J, Ritchie J. The role of GPs in sickness certification. (Research report 148). London: Department for Work and Pensions, 2001.

10. Hussey S, Hoddinott P, Wilson P, et al. Sickness certification system in the United Kingdom: qualitative study of views of general practitioners in Scotland. BMJ 2004; 328(7431): 88.

11. Hiscock J, Byrne P, Peters S, et al. Complexity in simple tasks: a qualitative analysis of GPs' completion of longterm incapacity forms. Primary Health Care Research and Development 2009; 10(3): 254-269.

12. Department of Work and Pensions. Desk Aid. http://www.gptraining.net/training/tutorials/management/sicknotes/ da2-advising-patients.pdf (accessed 5 Mar 2010).

13. Department of Work and Pensions. Statement of Fitness for Work. A guide for General Practitioners and other doctors.

http://www.dwp.gov.uk/docs/fitnote-gp-guide.pdf (accessed 5 Mar 2010)

DOI: 10.3399/bjgp10X483841

\section{ADDRESS FOR CORRESPONDENCE}

Mark B Gabbay

Head of Division of Primary Care,

University of Liverpool, Block B,

Waterhouse Buildings, 1-5 Brownlow

Street, Liverpool L69 3GL.

E-mail: M.B.Gabbay@liverpool.ac.uk 